\title{
Políticas da Comunicação no Novo Milénio: Crises, Impasses e Fracturas
}

\author{
Helena Sousa ${ }^{1}$ \\ Universidade do Minho
}

\begin{abstract}
Resumo: Este artigo aborda as medidas políticas e reguladoras subjacentes aos impasses $e$ às transformações na comunicação social, nas telecomunicações e na chamada Sociedade da Informação, em Portugal, no quinquénio 2000-2004. A análise centra-se fundamentalmente nos aspectos programáticos, tal como foram enunciados pelos actores centrais dos processos de decisão política, e na forma como determinadas medidas foram (ou não) implementadas. Este artigo está dividido em duas partes principais. A primeira é dedicada ao período entre 2000 e 2002, etapa em que o Partido Socialista dirigiu o país. A segunda parte dá conta dos desenvolvimentos que tiveram lugar no tempo dos governos maioritários de coligação PSDCDS/PP.
\end{abstract}

Palavras-chave: Políticas da Comunicação; Regulação; Sociedade da Informação; Telecomunicações; Media; Portugal.

\begin{abstract}
This article deals with the political and regulating measures underlying the gridlocks and the transformations in social communication, in telecommunication and in the so called Information Society in Portugal in the five years period of 2000-2004. The analysis is fundamentally centred in the pragmatic aspects as they were expressed by the central actors in the political decision processes, and in the form certain measures were (or not) implemented. This article is divided in two main parts. The first is dedicated to the period between 2000 and 2002 when the Socialist Party ran the country. The second part deals with the developments that took place during the PSD-CDS/PP government coalition.
\end{abstract}

Key Words: Communication Policies; Regulation; Information Society; Telecommunications; Media; Portugal.

\footnotetext{
1 Helena Sousa é professora associada e diretora do Departamento de Ciências da Comunicação da Universidade do Minho, além de investigadora do Centro de Estudos de Comunicação e Sociedade da mesma universidade. É vice-presidente da seção de Economia Política da International Association for Media and Communication Research e membro do EuroMedia Group. Integra o Editorial Board do European Journal of Communication. Organizou recentemente a coletânea Comunicação, economia e poder (Porto: Porto Editora, 2006).
} 


\section{Introdução}

As decisões políticas na esfera da comunicação articulam-se estritamente com os processos de decisão política mais abrangentes. A acção política sectorial joga-se necessariamente num pano de fundo onde múltiplos actores sociais desenvolvem as suas estratégias no sentido de defenderem os seus interesses. Neste breve capítulo, não poderemos dar conta dessa complexidade nem pretendemos tão-pouco abordar detalhadamente as medidas políticas e reguladoras subjacentes aos impasses e às transformações na comunicação social, nas telecomunicações e na chamada Sociedade da Informação. Procuraremos apenas apresentar e atribuir sentido a alguns desenvolvimentos que nos parecem particularmente relevantes.

O quinquénio anteriormente analisado no âmbito do Projecto Mediascópio, 19951999 (v. Pinto et al, 2000), cobre integralmente o primeiro mandato do governo de António Guterres². O período que agora procuramos examinar, 2000-2004, dá continuidade às políticas anteriores, num segundo governo com a mesma liderança ${ }^{3}$. O primeiro governo de António Guterres tinha apostado fortemente na Sociedade da Informação, tendo-a considerado uma prioridade nacional. Mas, à excepção das políticas desenvolvidas no âmbito da denominada Sociedade da Informação e, em certa medida, da imprensa regional (v. Ferreira, 2005; Amaral, 2005), não houve, ao longo desta legislatura, iniciativas notórias ou actividade verdadeiramente reformadora. Os impasses que haviam caracterizado o primeiro governo de António Guterres mantiveram-se durante o mandato seguinte que cobre quase integralmente a primeira metade do período em análise.

Ao imobilismo e aos impasses da governação de António Guterres sucedeu o forte ímpeto reformador do governo de Durão Barroso que liderou, com maioria absoluta, o executivo de coligação PSD-CDS/PP, desde Abril de 2002 a Julho de $2004^{4}$. Com o abandono das funções executivas a meio do mandato para assumir a Presidência da

\footnotetext{
2 O XIII governo constitucional governou de Outubro de 1995 a Outubro de 1999.

3 O XIV governo constitucional tomou posse em Outubro de 1999 e foi interrompido, por demissão do Primeiro-Ministro, em Abril de 2002.

4 O XV governo constitucional tomou posse em 6 de Abril de 2002 e terminou o seu mandato em 17 de Julho de 2004.
} 
Comissão Europeia, a direcção do executivo ${ }^{5}$ passou para as mãos de Pedro Santana Lopes que manteve as linhas gerais de acção traçadas pelo governo anterior. O quinquénio em apreciação nesta obra terminou durante a governação de Pedro Santana Lopes.

Neste artigo, iremos centrar a nossa análise em alguns aspectos programáticos, tal como foram enunciados pelos actores centrais dos processos de decisão política, e a forma como determinadas medidas foram (ou não) implementadas. Este artigo será dividido em duas partes principais. A primeira será dedicada ao período entre 2000 e 2002, etapa em que o Partido Socialista dirigiu o país. A segunda parte dará conta dos desenvolvimentos que tiveram lugar no tempo dos governos maioritários de coligação PSD-CDS/PP.

\section{Socialistas no poder: acção e inconsequências}

A primeira metade deste quinquénio (até Abril de 2002) ficou marcada pela continuidade em relação ao passado recente. $\mathrm{Na}$ sequência de um conjunto alargado de reformas estruturais no âmbito da comunicação e dos media durante os governos de Cavaco Silva (v. Sousa, 2000), o primeiro governo de António Guterres (1995-1999) manteve, no essencial, o status quo. Vários documentos legais foram revistos (Lei de Imprensa, Estatuo dos Jornalistas, Lei da Rádio, etc.), mas os grandes impasses nos media electrónicos, nos quais o Estado tem especiais responsabilidades ${ }^{6}$, mantiveram-se.

A mudança mais significativa relativamente às políticas anteriores teve lugar no âmbito da chamada Sociedade da Informação. O primeiro governo de António Guterres deu, de facto, uma grande importância às Tecnologias da Informação e da Comunicação (TICs), argumentando que a competitividade dos países estava intimamente ligada à forma como estes incorporam as TICs nos tecidos produtivo e social (v. Assembleia da República, 1995). Este empenho permaneceu durante o XIV governo constitucional que decidiu redobrar a aposta 'na plena integração de Portugal na Sociedade da Informação e do Conhecimento, até porque se pretendia 'ultrapassar no espaço de uma geração o atraso

\footnotetext{
5 O XVI governo constitucional tomou posse no dia 17 de Julho de 2004. Este executivo durou pouco mais de seis meses. Por decisão presidencial, foi dissolvida a Assembleia da República e as eleições legislativas foram marcadas para 20 de Fevereiro de 2005.

6 Ao contrário do que acontece na imprensa, a entrada e eventual permanência dos media electrónicos (rádio e televisão) no espaço público dependem de autorização estatal.
} 
estrutural que ainda nos separa do centro da União Europeia' (Assembleia da República, 1999: 3).

Numa articulação clara da Sociedade da Informação com o 'Universalismo Lusófono', o segundo governo de António Guterres entendeu que a sociedade da informação implicava grandes desafios ao país e ao lugar do país no mundo. 'A Sociedade da Informação coloca ao nosso alcance instrumentos tecnológicos que podem e devem ser postos ao serviço da afirmação do papel da língua e da cultura portuguesa à escala planetária' (Assembleia da República, 1999: 5). Tratava-se efectivamente de uma forte aposta transversal visando, entre outros aspectos, a promoção da generalização do uso da Internet, o alargamento do Programa Cidades Digitais a todo o país, o desenvolvimento de um programa que conduzisse à multiplicação dos conteúdos portugueses na Internet por mil (não há referência à base dessa multiplicação) e o lançamento e execução de um plano Nacional das Auto-estradas da Informação. (Assembleia da República, 1999:5-6).

O desenvolvimento de uma Sociedade da Informação transformou-se, portanto, na prioridade das prioridades e o III Quadro Comunitário de Apoio deu-lhe apoio específico. A Comissão Europeia aprovou em Julho de 2000 o Programa Operacional Sociedade da Informação (POSI) ${ }^{7}$ para um período de seis anos (2000-2006). Mesmo que não seja possível uma avaliação definitiva do programa $^{8}$, no final da governação de António Guterres, a OCDE (2002) afirmava que Portugal apresentava uma elevada taxa de penetração de bens e serviços em Tecnologias da Informação e da Comunicação, superior à de alguns parceiros europeus mais desenvolvidos. Considerando que em 2002 cerca de $40 \%$ dos lares tinham computador e cerca de metade acesso à Internet, Lurdes Macedo (2005) sustenta que é, todavia, preocupante o facto de estas evoluções não se repercutirem na qualidade e na quantidade do emprego. ' $O$ impacto do POSI na indução da empregabilidade em actividades competitivas ligadas às novas TIC parece (...) ficar aquém das expectativas' (Macedo, 2005: 89-90).

O desenvolvimento das TICs articula-se claramente com a expansão e a diversificação das telecomunicações. Ainda que por razões que transcendem a iniciativa

\footnotetext{
7 (www.posi.pcm.gov.pt/)

${ }^{8}$ Para uma análise (necessariamente provisória) da implementação do POSI, v. Macedo (2005: 71-93). 
política nacional, o sector das telecomunicações cresceu consideravelmente durante o primeiro mandato de António Guterres (v. Sousa, 2000). A partir de Janeiro de 2000, e já num contexto de total abertura de mercados (infra-estruturas e serviços, tanto de rede móvel como fixa), os responsáveis pela maior empresa nacional de telecomunicações, Portugal Telecom (PT), viam grandes perspectivas de negócio na convergência de conteúdos e distribuição. De resto, no plano internacional, o início do ano 2000 ficou marcado pela fusão do maior operador mundial de Internet, a AOL, e um dos maiores grupos multimedia globais, a Time Warner. Este negócio foi entendido como um modelo orientador para o desenvolvimento dos grandes operadores de telecomunicações e assumido como o padrão da convergência (v. Sousa e Silva, 2003).

Portanto, também para a PT, 2000 foi um ano de viragem. A estratégia adoptada foi precisamente a da expansão na área do audiovisual e dos media. Apesar das associações para a produção de canais temáticos com outros parceiros, a vocação da PT sempre foi a da distribuição. No entanto, no dia 3 de Abril de 2000, a Lusomundo e a PT Multimédia anunciam uma aliança que passava por uma OPA sobre as acções da Lusomundo dispersas em bolsa e a constituição de uma 'holding' em que a PT Multimédia passaria a ter 48\%. Em finais do ano, a PT acabou por controlar totalmente o grupo Lusomundo, tendo assim reconfigurado o panorama dos grandes grupos multi-media em Portugal.

O Presidente do Conselho de Administração da PT, Murteira Nabo, afirmou então que, 'a associação entre operadores globais de telecomunicações e grandes operadores de conteúdos tem-se generalizado em todo o mundo' e 'na chamada nova economia, quem dispõe de potentes plataformas de telecomunicações tem de juntar valor aos seus serviços, oferecendo propostas de conteúdos' (Público, 3 de Novembro de 2000: 41 in Sousa e Silva, 2003); Franquelim Alves, administrador da Lusomundo, defendeu, por seu lado, que 'a Lusomundo passará a contar com uma capacidade substancialmente maior para desenvolver projectos que aliem conteúdos aos canais de distribuição da PT' (Público, 3 de Novembro de 2000: 41 in Sousa e Silva, 2003).

Ainda que a 'inevitabilidade' de convergência não tivesse tardado a apresentar as suas fracturas (v. Sousa e Silva, 2003), não eram apenas os responsáveis pelas 
empresas que faziam esta leitura. No plano político nacional e internacional, esta visão era também largamente consensual. Assim, em 2001, foi criado, em Portugal, um grupo de trabalho para a Convergência e Regulação (Grupo de Reflexão da Iniciativa Convergência e Regulação, designado por Despacho Conjunto n. ${ }^{\circ}$ 987/2001, de 8 de Outubro de 2001) para repensar os desafios políticos e reguladores que se colocavam neste novo contexto. A ideia da convergência entre a distribuição e a produção implicaria mesmo, para este grupo de reflexão, a fusão dos organismos de regulação, tradicionalmente distintos, tendo-se alcançado consenso em torno da ideia de que a convergência aconselhará a concentração orgânica da regulação de conteúdos da regulação das redes e dos acessos, admitindo a possibilidade de uma entidade única ser responsável pela regulação das duas realidades, apesar dos interesses e dos valores divergentes que presidem a cada uma delas.

No caso da telefonia móvel, em 2000, aguardava-se também com algum entusiasmo a chegada do UMTS (Universal Mobile Telecommunications System). Ainda longe de prever o agravamento da situação financeira do país e confiante na alta rentabilidade do negócio futuro, o Governo colocou a concurso, no dia 1 de Agosto de 2000 (um mês antes da data prevista), quatro licenças de 15 anos, pelo valor de cem milhões de euros cada, tendo concorrido sete candidatos. Foram escolhidos os três operadores móveis já no mercado (TMN do universo PT, Telecel da Vodafone e Optimus da Sonae) e uma nova empresa, o consórcio Oniway, maioritariamente com capitais da ONI, empresa nascida da experiência de liberalização do mercado fixo de telefone em Portugal. Além do investimento inicial avultado, os vencedores comprometeram-se ainda a investir 1,5 mil milhões de euros na promoção do acesso universal ao novo serviço (Obercom, 2001/2992: 357). No entanto, as expectativas saíram goradas e, no início de 2003, para assegurar a sustentabilidade do mercado, os três operadores tradicionais das comunicações móveis compraram a quarta licença.

No âmbito da rádio e da televisão, o próprio programa do XIV governo reconhecia os impasses da legislatura anterior: Nos domínios da rádio e da televisão, estamos também numa encruzilhada. Continuará a garantir-se um sistema dual, que se 
constitui como património inquestionável na generalidade dos países europeus, onde as empresas de serviço público coexistem com um sector privado diversificado' (Assembleia da República, 1999). A falta de clareza relativamente aos objectivos a atingir no âmbito dos media electrónicos está, aliás, bem patente noutros momentos do documento programático: 'Tendo a RDP reencontrado o equilíbrio de gestão (...), estando a Lusa prestes a consolidar o equilíbrio financeiro (...), constituirá objectivo prioritário do governo determinar o custo socialmente suportável pelo país no financiamento da RTP. Nessa perspectiva, deverá ponderar-se não só o conjunto de serviços prestados e uma equilibrada gestão de recursos existentes, como as carências de diversos sectores da sociedade, e o nível proporcional das contribuições dos diferentes países europeus para o serviço público de televisão. O necessário saneamento económico e as condições de equilíbrio financeiro pressupõem um processo de reorganização da RTP e deverão sustentar-se num esforço plurianual, condição essencial para um desejável planeamento estratégico' (Assembleia da República, 1999).

A RTP vivia, de facto, no início do novo milénio, uma situação de crise profunda e o novo governo não se apresentava com ideias claras e com determinação para enfrentar esta dificuldade. Em audição parlamentar no dia 4 de Janeiro de 2000, o Presidente do Conselho de Administração da empresa na época, Brandão de Brito, traçou um quadro trágico da situação da empresa pública que se encontrava com um nível de endividamento insustentável. Apesar da sua insustentabilidade, a questão absolutamente crucial da dívida e do financiamento da empresa continuou adiada (v. Sousa e Santos, 2003).

Não obstante a ausência de taxa e as limitações à publicidade, não foram criadas quaisquer alternativas transparentes de financiamento da RTP e a ideia do então Secretário de Estado da Comunicação Social, Arons de Carvalho, de financiar a empresa através do estabelecimento de uma relação directa com o PIB não passou disso mesmo. As indemnizações compensatórias ficaram também sempre aquém do estabelecido e a imprevisibilidade das verbas colocadas à disposição da empresa impediam qualquer planeamento estratégico', tal como admitiu o próprio Secretário de Estado Socialista responsável pela tutela da Comunicação Social, poucos meses depois de ter abandonado o cargo (2002: 31). 
Em profunda crise financeira e identitária, a RTP foi alvo de todas as críticas. Não se julgue, porém, que essas críticas eram apenas e tão só da oposição. Inúmeras vozes internas ao PS, numa clara demonstração de desorientação estratégica, levantaram-se contra a sua lógica e desempenho. No dia 8 de Janeiro de 2001, Jorge Coelho congratulouse com o arranque da SIC- Notícias e teceu duras críticas ao trabalho desenvolvido pela RTP. Em Abril de 2001, outro destacado membro do partido no governo, António Costa, acusou a estação pública de não primar por um serviço informativo isento. Em Outubro de 2001, o socialista Manuel Maria Carrilho culpou o governo de nunca ter demonstrado qualquer preocupação relativamente aos problemas financeiros da RTP e criticou, no âmbito da discussão do Orçamento de Estado para 2002, na Assembleia da República, a atribuição de menos sete milhões de contos à RTP do que o prometido pelo governo.

Mais previsivelmente, se olharmos para a história da RTP, a oposição também acusava o governo de a instrumentalizar e, em Julho de 2001, a Comissão Permanente da Assembleia da República chegou a discutir as pressões do PS sobre a direcção de informação da RTP. A instabilidade sentida na empresa agravou-se ainda mais com o convite dirigido, em Setembro de 2001, ao ex-director da SIC e forte crítico da televisão pública, Emídio Rangel, para director-geral da estação de serviço público. As profundas divisões quanto a esta contratação eram internas à empresa, ao governo e ao parlamento, tendo a oposição exigido explicações ao governo sobre esta nomeação para o cargo.

Apesar da tentativa dos governos socialistas para afastar a RTP da subordinação directa à política de informação do executivo, a incerteza e a desorientação marcaram a televisão do Estado neste período (v. Sousa e Santos, 2003). O Presidente do Conselho de Opinião da RTP, António-Pedro Vasconcelos, sintetizava assim a situação que se vivia na empresa no início do novo milénio: «A RTP, tal como está, não pode continuar. Devido à falta de estratégia, à irresponsabilidade ou à incúria dos governos, à instabilidade das administrações, nomeadas na maioria dos casos em função da confiança política e não da sua competência, ao peso corporativo da nomenklatura interna, à falta de imaginação, criatividade e talento, que parecem ter desertado da programação, é hoje o principal obstáculo à existência de verdadeiro SPT em Portugal» (Público, 20 de Março de 2002: 41). 
Não tendo enfrentado as questões de fundo, o governo introduziu, no entanto, alterações na organização dos media sob a responsabilidade directa do Estado. Em 24 de Fevereiro de 2000, o Conselho de Ministros aprovou a criação da holding 'Portugal Global', entre a RTP, RDP e Lusa. A criação desta holding (Decreto-Lei 82/00) criou instabilidade adicional nas empresas, não tendo efectivamente resolvido nenhum problema estrutural.

De acordo com o então Secretário de Estado da Comunicação Social, Arons de Carvalho, a Portugal Global imitava o modelo de 'holding' criado noutros sectores da economia e visava gerir as participações do estado na RTP $(100 \%)$, na RDP $(100 \%)$ e na Lusa (então ainda com cerca de $97,2 \%{ }^{9}$ ), participar na reestruturação e saneamento financeiro da RTP, promover sinergias e intervir em novas áreas de negócio (2002: 80). Tendo em consideração os objectivos a que se propunha, a Portugal Global foi inconsequente $^{10}$. A Portugal Global criou, contudo, dificuldades de relacionamento entre as empresas do estado com equilibrio financeiro (LUSA e RDP) e a deficitária RTP (v. Carvalho, 2002: 79-86).

A profundidade da crise em que a RTP mergulhou transformou esta empresa do estado em objecto de todas as atenções na primeira metade do quinquénio em análise. Mas, no âmbito da televisão, outros esforços merecem destaque, nomeadamente os que envolveram o lançamento (e posterior suspensão) da televisão digital terrestre (TDT). No dia 9 de Janeiro de 2001, o primeiro-ministro, António Guterres, apresentou o modelo de televisão digital terrestre a implementar em Portugal que previa concursos distintos para o licenciamento da rede e dos canais. A Portugal Telecom ficaria impossibilitada de concorrer.

Preparando o caminho para o concurso que se avizinhava, a Impresa, a maior accionista da SIC, assinou um acordo de parceria com a RTP no sentido de concorrerem juntas à única licença de televisão digital terrestre com o grupo SGC, de João Pereira

\footnotetext{
${ }^{9}$ A entrada substancial de capitais privados na Lusa teve lugar em Julho de 2001.

10 A propósito da criação da holding Portugal Global, o então Secretário de Estado da Comunicação Social, Arons de Carvalho, terá dito ao Ministro-Adjunto, Armando Vara, que não a encarava como panaceia para os males da RTP, mas que a sua criação não teria igualmente consequências negativas: 'Digamos que não adiantava nem atrasava' (Carvalho, 2002: 79).
} 
Coutinho. Este consórcio (SGC, SIC e RTP) viu a sua candidatura aceite em Junho de 2001, tal como a da Oni Plataformas (com o grupo Media Capital). Em 17 de Julho do mesmo ano, o Instituto das Comunicações de Portugal anunciou que a PTDP, consórcio formado pelo grupo SGC, pela RTP e pela SIC, tinha conquistado o primeiro lugar no concurso para o operador de televisão digital terrestre. Em Outubro de 2001, o Instituto da Comunicação Social emitiu a licença que permitia o lançamento da televisão digital terrestre em Portugal e obrigou a PTDT a iniciar a actividade comercial até ao final de Agosto de 2002, o que não viria a acontecer. Mas se a televisão digital terrestre ficou num impasse, o mesmo não se pode dizer relativamente à televisão digital interactiva por cabo. A TV Cabo lançou este serviço em Portugal, em parceria com a Microsoft, em Junho de 2001.

A crise e os impasses no sector televisivo tiveram repercussões negativas no âmbito da produção audiovisual independente. Em entrevista ao Expresso (27 de Outubro de 2001), o presidente da Associação de Produtores de Cinema e do conselho fiscal da Associação dos Produtores Independentes de Televisão, Paulo Trancoso, considerava que a situação no sector audiovisual era grave. Para evitar a falência de algumas empresas Paulo Trancoso entendia que a solução seria o governo definir o audiovisual como um sector estratégico e criar medidas para um desenvolvimento sustentado. A crise económica (e consequente retracção das receitas publicitárias) fez com que as dívidas das estações de televisão aos produtores tivessem tornado a produção audiovisual particularmente difícil neste período. A solicitação de medidas urgentes ao governo teve lugar até ao final da governação socialista e prolongar-se-ia nas legislaturas seguintes.

Tendo sido reencontrado o equilíbrio de gestão da RDP, fortalecido com a assinatura do respectivo contrato de concessão, o segundo executivo de António Guterres concentrou-se na revisão da Lei da Radiodifusão. A Lei da Rádio 4/2001, de 23 de Fevereiro, procurava introduzir um maior rigor na respectiva actividade. Deixa de ser permitida a transmissão de alvarás (tanto por venda como por cedência gratuita) e as estações radiofónicas passam também a ter que transmitir 24 horas por dia. Enquanto a lei de 1999 fixava um período mínimo de 16, 10 ou 6 horas para, respectivamente, estações de cobertura geral, regional ou local, a lei de 2001 obrigava todas as emissoras a estarem sempre activas (v. Marinho, 2000; Santos, 2005). As rádios generalistas ficaram obrigadas a 
oito horas de programação própria por dia, incluindo três noticiários. A medida, tal como explicou Arons de Carvalho, visava contrariar a tendência de utilização de rádios, adquiridas e extintas por novos proprietários, para a criação de cadeias, com uma cobertura praticamente nacional (2002: 121). Outra questão relevante foi a atribuição de licenças a rádios temáticas que passou a ser possível apenas em concelhos com mais de uma frequência atribuída e nas áreas metropolitanas de Lisboa e Porto.

Para além da atenção, ainda que largamente inconsequente, dedicada aos media electrónicos, o segundo governo de António Guterres, e muito particularmente Arons de Carvalho, dedicou uma parte significativa do seu tempo ao dossier 'imprensa regional'. Já na anterior legislatura, este responsável havia proposto mexer neste complexo domínio, mas - tendo o partido do governo minoria parlamentar - não foi possível avançar com medidas legislativas. A minoria tangencial (a um deputado) trouxe, apesar de tudo, novas condições para alterar o status quo. Preocupado com a falta de visão estratégica de uma parte substancial dos cerca de 900 jornais locais e regionais, Arons de Carvalho entendia que a moralização e dinamização do sector passavam por uma revisão profunda do porte pago, que sustentava então, na totalidade, a distribuição de centenas de títulos (v. Carvalho, 2002; Ferreira, 2005).

Apesar dos fortes protestos de praticamente todas as associações ligadas à imprensa regional e local e da oposição social-democrata no parlamento, o governo conseguiu aprovar o Decreto-Lei 56/2001 de 19 de Fevereiro, com o apoio do Bloco de Esquerda (v. Ferreira, 2005). Aplicado a publicações cujo peso não ultrapassasse os duzentos gramas, este diploma determina que a expedição passa a ser comparticipada em $95 \%$, se o jornal for enviado para um assinante residente no estrangeiro (artigo $5^{\circ}$ ). No que diz respeito à expedição para território nacional, os jornais passariam a beneficiar de uma comparticipação de $80 \%$, desde que um conjunto de condições (de natureza laboral e de circulação) fossem garantidas (v. artigo 6 do referido diploma). De acordo com Ferreira, a redução do porte pago na imprensa regional teve efeitos 'exíguos', mas o Governo Socialista estaria a partir a pedra para uma necessária reforma no sector $(2005: 171)$. 


\section{Coligação PSD/CDS-PP: A ideologia da ruptura}

Ainda que o segundo governo de António Guterres tivesse no seu horizonte mais dois anos de governação, a demissão do Primeiro-ministro precipitou a vitória do PSD que, em coligação com o CDS-PP, constituiu o XV e o XVI governos constitucionais, liderados, respectivamente, por Durão Barroso e Pedro Santana Lopes. Procurando contrariar a imagem de imobilismo e impasses decorrentes em larga medida das lutas internas ao Partido Socialista, os governos da coligação assumiam-se publicamente como executivos de acção reformada e, frequentemente, de ruptura.

No entanto, mesmo na vasta esfera das comunicações e dos media, verificaram-se posturas diferenciadas, de acordo com as especificidades dos diversos sectores e subsectores. No que diz respeito às políticas para a Sociedade da Informação e para as Telecomunicações, a aposta transversal dos socialistas seria para manter. Por razões de natureza interna e fundamentalmente externa, estas eram áreas de grande consenso. A política europeia desenvolvia-se no sentido da intensificação da penetração das novas tecnologias da informação e da comunicação, da expansão das redes electrónicas de banda larga e da implementação de medidas relativas à abertura total dos mercados das telecomunicações e das tecnologias da informação. As próprias Nações Unidas estavam activamente empenhadas em promover o acesso e uma mais eficaz utilização das redes electrónicas em todo o mundo, nomeadamente através do envolvimento de entidades públicas e privadas na Cimeira Mundial da Sociedade da Informação.

Seguindo a mesma linha de raciocínio dos governos socialistas quanto à relevância estratégica da Sociedade da Informação, o XV governo constitucional entendeu que a abordagem relativamente à Sociedade da Informação deveria ser transversal e, por isso, tal como já previa o seu programa de governo (v. Assembleia da República, 2002), tornou-se uma das áreas de liderança e de coordenação do próprio Primeiro Ministro (ainda que estas funções tenham sido posteriomente delegadas no Ministro Adjunto do Primeiro Ministro). Neste contexto, foi criada pela Resolução do Conselho de Ministros nº 135/2002 de 20 de Novembro a Unidade de Missão Inovação e Conhecimento, à qual coube a tarefa de propor detalhadamente uma estratégia de desenvolvimento da Sociedade da Informação 
para o período de 2003-2006, os planos de acção para a sua operacionalização e a monitorização da respectiva execução.

Em Junho de 2003, o Conselho de Ministros aprovou um conjunto de documentos estratégicos para a Sociedade da Informação, desenvolvidos já sob a coordenação directa daquela Unidade de Missão: o Plano de Acção para a Sociedade da Informação, a Iniciativa Nacional para a Banda Larga, o Programa Nacional das Compras Electrónicas e o Programa para a Participação dos Cidadãos com Necessidades Espaciais na Sociedade da Informação (v. www. Umic.pcm.gov/UMIC), acesso em 15 de Novembro de 2005). Para além da elaboração dos planos de acção, a UMIC desempenhou um papel activo no desenvolvimento de várias iniciativas em torno da massificação do acesso e utilização da Internet de banda larga, nomeadamente nas escolas públicas dos ensinos básico e secundário.

Precisamente no sentido de reforçar as medidas do XV governo constitucional relativamente à Sociedade da Informação, o governo de Pedro Santana Lopes mantém i) o alinhamento com as políticas europeias nesta matéria, nomeadamente o compromisso dos estados-membros relativamente à Estratégia de Lisboa e aos Planos de Acção eEurope 2002 e 2005; ii) o reforço da liderança, coordenação transversal e capacidade de implementação, assegurada na dependência da Presidência do Conselho de Ministros e iii) a execução dos Planos de Acção para a Sociedade da Informação aprovados em Conselho de Ministros em 2003 (Assembleia da República, 2004).

No âmbito das telecomunicações, e considerando que o mercado se encontrava já totalmente liberalizado desde Janeiro de 2000, as preocupações políticas na segunda metade do quinquénio em análise centravam-se essencialmente em garantir os mecanismos reguladores necessários ao desenvolvimento de um mercado aberto e competitivo. $\mathrm{O}$ objectivo fundamental do XV governo nesta área consistia, pois, 'no incremento do rápido nível de progresso tecnológico do sector, cujas características especiais recomendam a manutenção de uma autoridade reguladora independente, com poderes em matéria de verificação dos níveis de concorrência e de qualidade do serviço.' (Assembleia da República, 2002). A independência desta autoridade era vista pelo Governo como condição 
imprescindível para a credibilização das decisões do executivo e consequente imagem junto de clientes e investidores, das empresas cotadas do sector. $O$ processo de convergência reguladora ficava, portanto, pelo caminho, propondo-se o governo a manter a tradicional distinção entre a regulação dos conteúdos e a regulação dos mercados de distribuição. De resto, os próprios operadores de telecomunicações em Portugal e no estrangeiro (ex: Portugal Telecom e Telefónica) davam sinais de desinvestimento na produção de conteúdos e regressavam paulatinamente ao núcleo central das suas actividades - a distribuição.

Para além da intenção de garantir a independência e eficácia da entidade reguladora das Comunicações, o XV governo admitia, no entanto, que, nos casos em que determinadas tecnologias fossem identificadas como cruciais para o desenvolvimento do país, mas cuja exploração se pudesse revelar pouco interessante para operadores privados, o Estado promoveria o licenciamento da exploração das mesmas por concurso público, outorgando as licenças sobretudo em função da solidez tecnológica da proposta e das contrapartidas pretendidas, as quais deveriam ser concedidas preferencialmente sob a forma de crédito fiscal de imposto ou similar concedido aos promotores. O governo propunha-se ainda a apoiar e a promover as empresas nascentes que se dedicassem ao desenvolvimento de novos serviços de base tecnológica virados para as telecomunicações, nomeadamente através dos apoios disponíveis em matéria de investigação científica aplicada e sob a forma de participações de capital de semente (Assembleia da República, 2002). O XVI governo dizia-se disposto a manter as linhas de acção traçadas pelo executivo de Durão Barroso.

O desenvolvimento de uma verdadeira Sociedade da Informação (ainda que centrada na expansão do acesso e não na ampliação de competências para uma utilização significativa) era reconhecido pela classe política como natural e inevitável para aproximar o país dessa Europa sempre distante. As medidas levadas a cabo neste âmbito não causaram, portanto, qualquer controvérsia relativamente à visão de futuro que incorporavam. O mesmo não poderá ser dito em relação à acção dos governos de coligação PSD/CDS-PP no âmbito da comunicação social, em geral, e muito particularmente em relação à sua visão sobre o papel do Serviço Público de Televisão. 
Considerando que os governos de coligação formavam maiorias absolutas e que o PSD, ainda na oposição, defendera, no dia 23 de Janeiro de 2002, na Assembleia da República, o fim da publicidade na RTP1, a venda em concurso público da RTP 2 e a extinção da Portugal Global, esperavam-se mudanças profundas neste sector. O Programa do XV Governo (Assembleia da República, 2002) também não deixava dúvidas a este nível. Considerando que a RTP acumulara um passivo absolutamente incomportável e que assumia a dimensão de verdadeiro escândalo público, a resolução deste problema foi entendida como uma prioridade para o governo, ainda que fosse necessário, tal como dá conta o Programa do Governo, integrar a reestruturação da RTP numa visão mais ampla de todo o sector público dos media, redefinindo a dimensão e o perfil da RDP e a participação e o financiamento do Estado na agência Lusa.

Concretamente em relação à RTP, o governo propunha-se a adoptar as seguintes medidas: i) a realização de uma análise de gestão, organizacional e financeira, num curtíssimo prazo e com datas bem definidas; ii) a aplicação de um plano financeiro de curto prazo, por forma a resolver alguns problemas imediatos; iii) a cisão em duas empresas da actual RTP, S.A., permanecendo apenas uma delas, com a titularidade de uma só licença de televisão, sob a responsabilidade do Estado; iv) a concentração na empresa que ficará sob a responsabilidade do Estado do serviço público de televisão, através de um canal generalista e da conjunção da RTP Internacional e da RTP África; v) a verificação da possibilidade de rentabilizar os activos da RTP, nomeadamente através da venda ou concessão, aplicando as receitas aí geradas na resolução do passivo; vi) a quantificação, de forma rigorosa, do custo real do serviço público de televisão e a procura de formas de garantia do respectivo financiamento, sem prejudicar o normal funcionamento do mercado e com limites previamente fixados; vii) a fixação de padrões de qualidade para o canal generalista (...); viii) a transformação da RTP Internacional e da RTP África, agindo em conjunção, em verdadeiros instrumentos de uma política de defesa da identidade nacional, no primeiro caso, e de cooperação, no segundo; tal implica rever toda a estrutura de produção de conteúdos, que devem deixar de ser um exclusivo da RTP; ix) a autonomização, no respeito das regras de prestação de serviço público atrás referidas, dos Centros Regionais dos Açores e da Madeira, em condições a determinar e mediante 
adequadas negociações com os respectivos Governos Regionais (Assembleia da República, 2002).

Relativamente à RDP o Governo pretendia proceder à reorganização da actual estrutura da empresa de forma a ajustá-la às funções específicas de um serviço público de radiodifusão, combatendo o desperdício; à concentração da sua actividade num canal generalista (RDP 1) e na RDP Internacional; à rentabilização, considerando a situação de mercado actualmente existente e os operadores que nele actuam, dos activos da empresa, alienando a Antena 3 e avaliando um novo modelo para a Antena 2; à aplicação das receitas geradas com as operações atrás referidas na reestruturação do sector audiovisual do Estado; à valorização e dignificação do importante papel da RDP no espaço nacional, no espaço lusófono e nas Comunidades Portuguesas. Neste contexto, a agência Lusa não ficaria de fora. O Governo pretendia ainda avaliar a sua participação na agência, numa lógica que salvaguardasse o papel de uma agência de informação no espaço da língua portuguesa e com um quadro de financiamento rigoroso. $\mathrm{O}$ corolário das medidas que o Governo preconizava para este sector seria a extinção da Portugal Global (Assembleia da República, 2002).

Nem todas as medidas propostas no programa do governo foram efectivamente implementadas, mas o impulso reformador perceptível nestas linhas resultou efectivamente em acção política. O objectivo de criar um novo canal (em substituição da RTP2) que 'fizesse' Serviço Público fora do operador de Serviço Público terá sido porventura a mais polémica opção governamental (v. Capítulo x desta obra). O governo defendia um canal feito pelo público para o público, sem intermediação do Estado. Numa fase inicial, o desenvolvimento deste canal deveria ser apoiado pela RTP, mas ganharia uma concessão autónoma após oito anos de 'regime transitório' (Lei da Televisão, no 32/2003 de 22 de Agosto, artigo $5^{\circ}$ ). Ainda que a RTP não tivesse deixado de ser o motor deste segundo canal, $A$ Dois (ou 2:) arrancou efectivamente as suas emissões no dia 5 de Janeiro de 2004 com uma contribuição significativa de programas da responsabilidade da denominada 'sociedade civil' e com uma lógica distinta da do Canal 2 que o precedeu. 
A amputação simbólico-formal de um canal generalista à empresa-mãe foi apenas uma entre as inúmeras transformações em que a RTP se viu envolvida. Na sequência da extinção da holding Portugal Global que concentrava a RTP, RDP e a Lusa, foi criada ${ }^{11}$ a holding Rádio e Televisão de Portugal que passou a congregar a RTP, a RDP, a RTP Meios de Produção (resultante da fusão da FOCO e da EDIPIM, novos operadores regionais de televisão (que se pretendia autonomizar), a SPORTV (que se queria alienar) e ainda a empresa provisória para o Euro 2004 (EBS 2004). Numa lógica de redução de custos, a nova holding foi progressivamente fundindo serviços e instalações até então autónomos. Para além das medidas de contenção de custos, nomeadamente na área dos recursos humanos, e do controle de produtividade, através da implementação de mecanismos de avaliação, a RTP e a RDP passaram a ter também um novo modelo de financiamento.

A Lei do Financiamento do Sector Público de Radiodifusão e Televisão, aprovada pela Assembleia da República, em Julho de2003, previa que as duas empresas da nova holding fossem financiadas pela contribuição para o audiovisual (na prática, uma taxa paga juntamente com a conta da electricidade) e pelo Orçamento de Estado. As receitas de publicidade da RTP (reduzidas para um máximo de 6 minutos por hora na RTP1 e proibida n' $A$ Dois) teriam que ser utilizadas exclusivamente para financiar o serviço da dívida e, posteriormente, em novos investimentos. As receitas da publicidade deixaram, portanto, de ser utilizadas para despesas correntes da empresa. No sentido de criar condições para uma mais gestão mais eficaz dos recursos o financiamento público da RTP passaria a ser fixado por períodos de quatro anos, embora com especificação das parcelas transferíveis anualmente do Orçamento de Estado. Este esforço de racionalização financeira sortiu efeitos e o Presidente da holding Rádio e Televisão de Portugal, Almerindo Marques, anunciava em Setembro de 2004 - em entrevista ao Diário de Notícias - que os resultados financeiros da RTP no primeiro semestre do ano tinham sido positivos, o que seria considerado um marco histórico para a estação (Diário de Notícias, 27.09.2004).

\footnotetext{
${ }^{11}$ Lei da Reestruturação do Sector Empresarial do Estado na Área do Audiovisual
} 
Ao contrário do que estava previsto, os canais internacionais RTP Internacional e RTP África mantiveram-se independentes por razões que se prendiam com esse desígnio sempre maior de afirmar Portugal no Mundo. A Antena 3, cuja alienação estivera também prevista, manteve-se na esfera da RDP 'por se considerar um activo estratégico na renovação dos quadros daquela empresa e por promover efectivamente a música portuguesa e as novas tendências' (Duarte, 2005: 29).

As políticas governamentais para os media electrónicos não esgotaram nos media de serviço público. A lei da Televisão de 2003 continha também a explicitação de um conjunto de obrigações gerais para todos os operadores de televisão. Foi introduzido o conceito de ética de antena e feita uma revisão do regime sancionatório aplicável à actividade televisiva. Mas o Ministro da Presidência, Morais Sarmento, dizia-se igualmente preocupado com a viabilidade financeira das televisões privadas generalistas e de todo o sector audiovisual. Assim, e perante a possibilidade de redução da publicidade na RTP 1 de 7,5 para 6 minutos por hora (durante a governação de António Guterres passou de 12 minutos para 7,5), o governo pediu 'contrapartidas aos operadores privados nas áreas do apoio e promoção à produção independente de cinema e televisão, e na cedência de conteúdos e de programação cultural' (Duarte, 2005:28). Em Agosto de 2003 estabeleceuse efectivamente um protocolo que previa a cedência de conteúdos dos canais privados aos canais internacionais da RTP, o pagamento das dívidas ao ICAM, o pagamento das dívidas aos produtores independentes e (reconhecendo o estado a sua incapacidade para implementar a lei) o fim da ultrapassagem dos limites publicitários legalmente estabelecidos. A nova lei do Cinema e Audiovisual, aprovada em Assembleia da República, no dia 1 de Julho de 2004, previa também uma diversificação das formas de financiamento do sector e a participação dos distribuidores de cinema e dos operadores de televisão no apoio à produção audiovisual. $\mathrm{Na}$ esfera radiofónica, em Setembro de 2003, foram aprovadas as propostas de lei do CDS-PP e do PS para a regulamentação das quotas de música portuguesa a serem transmitidas pela rádio.

Contrariando este curso reformista, a televisão digital terrestre manteve-se, durante os XV e o XVI governos constitucionais, num impasse. O arranque da TDT deveria ter ocorrido em Setembro de 2002, mas tal não aconteceu. Com base num parecer da entidade 
reguladora das telecomunicações, ICP-Anacom, o Ministério da Economia decidiu adiar o prazo para o início do mês de Março de 2003. Data que acabou por não ficar marcada pela entrada em funcionamento da televisão digital, mas pela revogação da licença. O ministro da Economia, Carlos Tavares, seguiu o parecer emitido pela Anacom que, analisando o desenvolvimento do projecto de televisão digital, 'entendeu que existem dificuldades objectivas na sua implementação', e deu, consequentemente, um parecer no sentido da anulação da atribuição da licença à PTDP (Diário de Notícias, 14 de Março de 2003: 52).

Na base do parecer da Anacom estava a impossibilidade de lançar comercialmente e de forma massificada a TV digital em Portugal. Isto porque a tecnologia MHP, escolhida como plataforma standard da União Europeia, estava numa fase de teste e, segundo Pereira Coutinho, este processo deverá demorar mais do que um ano a estar concluído. 'Há uma impossibilidade total de cumprimento de prazos. E a verdade é que as set top boxes não existem nem em Portugal nem em nenhuma parte do mundo, e não sei porque teríamos de ser os primeiros' diz Pereira Coutinho (in Diário de Notícias, 14 de Março de 2003: 52). O consórcio PTDP havia solicitado ao executivo um novo adiamento, mas perante as incertezas quanto ao tempo que demorará para que haja condições de massificação, a opção governamental recaiu na revogação da licença. $\mathrm{O}$ fracasso da tecnologia e do modelo comercial em Espanha e no Reino Unido terá estado na base da re-avaliação do lançamento da Televisão Digital Terrestre.

No encalço dos esforços desenvolvidos pelo Secretário de Estado da Comunicação Social dos governos de António Guterres, os governos de coligação PSD-CDS/PP deram seguimento à redução progressiva do apoio do estado à imprensa regional. Argumentando a favor de uma solução intermédia entre o modelo liberal (defendido para outras esferas económicas) e o modelo proteccionista, o objectivo final da actuação destes executivos nesta esfera seria, nas palavras do Secretário de Estado Adjunto do Ministro Adjunto do Primeiro Ministro, Feliciano Barreiras Duarte, 'fortalecer o tecido empresarial do sector e proporcionar-lhe um choque qualitativo, de forma a que, no médio prazo, o Estado possa reduzir o seu peso na informação de proximidade' (2005: 17). Para chegar ao modelo intermédio (também designado 'empresarial'), o Conselho de Ministros liderado por Pedro 
Santana Lopes aprovou, em 7 de Outubro de 2004, um conjunto de diplomas ${ }^{12}$ que visavam contribuir definitivamente para a retirada gradual do Estado do sector e para a profissionalização da imprensa regional e local. Entre as inúmeras alterações previstas neste pacote legislativo, destaca-se a redução da comparticipação média do Estado para 50\% dos custos de expedição e o termo de qualquer apoio à expedição (findo os três anos de regime de transição), caso os jornais não profissionalizem os seus quadros.

\section{Notas Conclusivas}

Durante o primeiro quinquénio do novo milénio, os governos socialista e de coligação PSD-CDS/PP deram grande atenção (ainda que nem sempre consequente) à chamada Sociedade da Informação e aos media electrónicos, com particular incidência no operador público de televisão. No que toca à Sociedade da Informação, os socialistas (desde o primeiro governo de António Guterres até ao actual governo de José Sócrates, já fora do âmbito estrito desta análise) assumiram a liderança no reconhecimento do valor estratégico das TICs para o desenvolvimento de uma sociedade baseada no conhecimento e na inovação. No que toca ao reconhecimento da insustentabilidade da RTP, nos moldes em que operava, é notório que os governos de coligação PSD-CDS/PP tiveram um papel bem mais determinado e resultante.

Mantendo-se fiéis a uma preocupação de todos os governos, desde o tempo de Cavaco Silva, os três executivos considerados neste período deram também particular relevo à afirmação de Portugal, da sua língua e cultura no Mundo. Os canais públicos de rádio e de televisão (e, mais recentemente, com a contribuição dos operadores privados de televisão) continuaram a ser vistos como instrumentos fundamentais (e inquestionáveis) para a progressiva afirmação externa do país. A necessidade de uma reforma da política para a imprensa regional centrada na progressiva retracção do estado, procurando evitar a proliferação de títulos ao arrepio de qualquer sustentação económica e profissionalismo, foi outro aspecto de convergência política. As próprias metodologias de acção foram

12 Decreto-Lei $n^{\circ}$ 224/2004, de 4 de Dezembro, que altera o Código da Publicidade, Decreto-Lei $n^{\circ}$ 231/2004, de 13 de Dezembro, que regula a distribuição da publicidade do Estado, Decreto-Lei nº/2005, de 6 de Janeiro, que estabelece o regime de porte pago e Decreto-Lei $n^{\circ} 7 / 2005$, de 6 de Janeiro, que cria o sistema de incentivos do Estado à comunicação social. 
semelhantes. Os respectivos secretários de estado com responsabilidades na matéria calcorrearam o país de lés a lés, auscultando centenas de jornais e respectivas associações, procurando neutralizar as previsíveis (e temidas) resistências à retracção dos subsídios estatais.

No âmbito da regulação das comunicações e dos media, o início da década ficou marcado pela percepção de que a convergência da regulação seria uma consequência natural da convergência tecnológica. Arons de Carvalho, considerou - em vários momentos - a possibilidade da criação de um organismo de regulação que integrasse os Media e as Telecomunicações, como aconteceu no Reino Unido com a OFCOM. Em entrevista ao Jornal Público (03.09.2001), o Presidente do Instituto de Comunicações de Portugal, Luís Nazaré, argumentava também que fazia sentido um regulador único para as telecomunicações e para o audiovisual. No entanto, à medida que as grandes operadoras de telecomunicações se iam afastando do negócio dos media, esta visão foi esmorecendo e regressa-se à tradicional distinção reguladora entre conteúdos e distribuição.

Mas, ao contrário da Anacom, que se foi consolidando como mecanismo autónomo de regulação das telecomunicações e que entrou já em velocidade de cruzeiro, a Alta Autoridade para a Comunicação Social não conseguiu impor-se perante a classe política nem perante a classe jornalística. A percepção de que se tratava de uma entidade ineficaz traçou-lhe o destino. Os grandes partidos confluíam na vontade de a extinguir e o grande consenso - necessário às transformações constitucionais - foi conseguido. A Alta Autoridade para a Comunicação Social foi extinta em Abril de 2004, tendo-se mantido em funções até que seja definida a entidade substituta.

Em dois aspectos, porém, os governos socialista e de coligação divergiram substancialmente: no estilo de governação e na relação com os media. Assumindo um discurso de ruptura contra o imobilismo e de afronta directa aos interesses que se moviam na sombra, o pivot da política da coligação para os media, Morais Sarmento, distanciou-se do estilo de governação anterior. Ao contrário do que havia sucedido na primeira metade do período aqui em análise, os governos da coligação quiseram distinguir-se pela fuga ao gradualismo e pela rompimento com o que diziam ser o inimigo público: os lobbies e os 
interesses ocultos. A urgência reformista - que no caso do Serviço Público de Televisão inviabilizou um amplo e necessário debate - contrastou com a preocupação socialista de manter (interminavelmente) abertos canais de diálogo, o que - em diversas circunstâncias inviabilizou a acção.

$\mathrm{Na}$ relação entre o executivo e os media, o governo socialista desenvolveu esforços no sentido de manter uma relação cordata e, aparentemente, distanciada. Apesar das críticas da oposição, o governo socialista dizia-se empenhado em garantir a independência da comunicação social face aos poderes. Não problematizando aqui as medidas nem as condições para essa eventual independência, é - no entanto - de salientar que a mesma preocupação não parece ter presidido a algumas opções dos governos de coligação.

A tentativa de criação do novo gabinete de comunicação e informação do Governo, conhecido por 'Central de Comunicação', levantou fortes suspeitas relativamente às intenções do executivo na sua relação com os media, tendo o Presidente da República acabado por chumbar o projecto. A tese defendida por Morais Sarmento, em Setembro de 2004, de que deve ser o Governo a definir o modelo de programação da RTP, explicando que era necessário 'haver limites à independência' dos operadores públicos em nada contribuiu para o melhoramento das já tensas relações. O presidente do Sindicato dos Jornalistas, Alfredo Maia, considerou, na altura, que as afirmações do ministro da Presidência sobre a RTP revelavam uma 'visão instrumental dos órgãos de comunicação social por parte do Governo’.

Por fim, o hiper-mediatizado 'Caso Marcelo': o popular comentador da estação privada TVI deu por terminada, em Outubro de 2004, a sua colaboração de há quatro anos nesta estação televisiva. Atendendo a que esta decisão foi anunciada poucos dias depois do Ministro dos Assuntos Parlamentares, Rui Gomes da Silva, se tem manifestado desagradado com o discurso crítico daquele destacado membro do Partido Social Democrata em relação ao governo liderado pelo (também) social democrata, Pedro Santana Lopes, as suspeitas avolumaram-se. A oposição não perdeu esta oportunidade para explorar a ideia de que se tratava de uma ingerência directa do próprio governo nas opções editoriais de uma estação privada. Ainda que a verdade dos factos sobre este caso não 
esteja ainda devidamente apurada, é claro que este desenvolvimento, aliado a muitos outros, terá contribuído para o desenvolvimento da percepção pública de que o último governo da coligação actuava de forma intempestiva e incauta.

\section{Bibliografia}

Amaral, Victor (2005) 'Imprensa Regional e Políticas da Comunicação: Situação geral no quadriénio 1999-2000’ in Comunicação e Sociedade, vol. 7.

Assembleia da República (2004). Programa do XV governo Constitucional, Apresentação e Debate. Lisboa: Assembleia da República.

Assembleia da República (2002). Programa do XV governo Constitucional, Apresentação e Debate. Lisboa: Assembleia da República.

Assembleia da República (1999). Programa do XIV governo Constitucional, Apresentação e Debate. Lisboa: Assembleia da República.

Assembleia da República (1995). Programa do XIII governo Constitucional, Apresentação e Debate. Lisboa: Assembleia da República.

Barata-Feyo, José Manuel (2002). RTP: O Fim Anunciado. Lisboa: Oficina do Livro.

Carvalho, Alberto Arons (2002). Valerá a Pena Desmenti-los? Coimbra: Minerva.

Duarte, Feliciano Barreiras (2005) Informação de Proximidade, Jornais e Rádios, Âncora: Lisboa.

Faustino, Paulo (2005) A Imprensa em Portugal, Transformaçõs e Tendências, Lisboa: Media XXI.

Ferreira, Paulo (2005) 'O Custo das Não-decisões na Imprensa Local e Regional em Portugal' in Comunicação e Sociedade, vol. 7.

Macedo, Lurdes (2005) 'Políticas para a Sociedade da Informação em Portugal: Da Concepção à Implementação', in Comunicação e Sociedade, vol.7, 2005, pp. 71-93.

Marinho, Sandra. (2000) 'Um percurso da rádio em Portugal' in Pinto et al. (Coord.) Televisão e Cidadania, Contributos para o debate sobre o serviço público, Braga: Núcleo de Estudos de Comunicação e Sociedade, Universidade do Minho.

OBERCOM - Observatório da Comunicação (2000/2001) Anuário Comunicação 2000/2001, Lisboa : Obercom.

OBERCOM - Observatório da Comunicação (2001/2002) Anuário Comunicação 2001/2002, Lisboa : Obercom.

OBERCOM - Observatório da Comunicação (2002/2003) Anuário Comunicação 2002/2003, Lisboa : Obercom. 
OBERCOM - Observatório da Comunicação (2003/2004) Anuário Comunicação 2003/2004, Lisboa : Obercom.

OBERCOM - Observatório da Comunicação (2004/2005) Anuário Comunicação 2004/2005, Lisboa : Obercom.

OECD (2002) Measuring the Information Economy in www.oecd.org/sti/measuringinfoeconomy.

Pinto et al. (Coord.) (2000) A Comunicação e os Media em Portugal (1995-1999) Cronologia e Leituras de Tendências, Departamento de Ciências da Comunicação, Universidade do Minho: Braga.

Pinto et al. (Coord.) (2003) Televisão e Cidadania, Contributos para o debate sobre o serviço público, Núcleo de Estudos de Comunicação e Sociedade, Universidade do Minho: Braga.

Presidência do Conselho de Ministros. (19.12.2002). 'Novas Opções para o Audiovisual'.

Santos, Rogério (2003) 'Rádio Clube Português - da escassez de frequências à grande importância no meio radiofónico nacional (1931-1936)'. Media \& Jornalismo, 3: 51-66.

Santos, Rogério (2005) 'Rádio em Portugal: tendências e grupos de comunicação na actualidade' in Comunicação e Sociedade, Vol. 7.

Silva, Elsa Costa e. (2004) Os donos da notícia - concentração da propriedade dos media em Portugal, Porto: Porto Editora.

Sindicato dos Jornalistas (2003) Por uma agenda dos poderes públicos para os media, Lisboa: Sindicato dos Jornalistas

Silva, Aníbal Cavaco (1995) As Reformas da Década (1986-1995), Venda Nova, Bertrand.

Sousa, Helena (1996) Communications Policy in Portugal and its Links with the European Union, An Analysis of the Telecommunications and Television Broadcasting Sectors from the mid-1980s until the mid-1990s, Londres, School of Social Sciences, City University (Tese de Doutoramento).

Sousa, Helena (1999a) The Liberalisation of Media and Telecommunications in Portugal, comunicação apresentada na Conferência Portugal ath the Millenium, organisada pelo Centre for Entreprise and Economic Development Research, Canning House, Londres, 21 de Maio.

Sousa, Helena (1999b) "Portugal" in Legal Guide to Audiovisual Media in Europe, Recent Legal Developments in Broadcasting, Film, Telecommunications and the Global Information Society in Europe and Neighbouring States, European Audiovisual Observatory, Estrasburgo.

Sousa, Helena (1999c) "Serviço Público, Televisão Comercial e a Implementação da Lei: Alguns Elementos para o Debate“ in Comunicação e Sociedade I, Cadernos do Noroeste, Série Comunicação, Vol.12 (1-2), pp.121-130.

Sousa, Helena (1999d) Os Media ao Serviço do Imaginário, Uma breve Reflexão sobre a RTP Internacional e a Lusofonia, Comunicação apresentada na Sessão 
Temática "Informação e Jornalismo" do III Encontro Lusófono de Ciências da Comunicação subordinada ao tema "Investigação: Convergência e Desafios", Universidade do Minho, Braga, 27-30 de Outubro.

Sousa, Helena (2000) 'Políticas da Comunicação: Reformas e Continuidades' in Pinto et al. (Coord.) A Comunicação e os Media em Portugal (1995-1999) Cronologia e Leituras de Tendências, Departamento de Ciências da Comunicação, Universidade do Minho: Braga.

Sousa, Helena (2002) «The liberalisation of Media and Communications in Portugal» in Stephen Syrett (Ed.) Contemporary Portugal, Dimensions of Economic and Political Change, Aldershot (UK) \& Burlington (USA): Ashgate.

Sousa, Helena e Luís António Santos (2003) 'RTP e Serviço Público, um percurso de inultrapassável dependência e contradicção' in Pinto et al. (Coord.) Televisão e Cidadania, Contributos para o debate sobre o serviço público, Núcleo de Estudos de Comunicação e Sociedade, Universidade do Minho: Braga.

Sousa, Helena e Elsa Costa e Silva (2003) «Os Caminhos Incertos da Convergência: O Caso da Portugal telecom» in Redes. Com, Revista de Estudios para el Desarrollo Social de la Comunicación., Instituto Europeu de Comunicación y Desarrollo, Sevilha.

Presidência do Conselho de Ministros. (11.11.2002). 'XV governo Constitucional - Os primeiros seis meses - Estamos a Cumprir - Portugal vai Vencer'. http://www.portugal.gov.pt/pt/Documentos/20021111SeisMeses1.htm 